\title{
Prevalence of metabolic syndrome in Saudi Arabia - a cross sectional study
}

\author{
Khalid Al-Rubeaan ${ }^{1 *}$, Nahla Bawazeer ${ }^{2}$, Yousuf Al Farsi ${ }^{1}$, Amira M. Youssef ${ }^{3}$, Abdulrahman A. Al-Yahya $^{4}$, \\ Hamid AlQumaidi', Basim M. Al-Malki ${ }^{1}$, Khalid A. Naji', Khalid Al-Shehri ${ }^{1}$ and Fahd I. Al Rumaih ${ }^{4}$
}

\begin{abstract}
Background: The evaluation of metabolic syndrome in a society predisposed to the diabetes mellitus epidemic opens a new avenue to understanding this rapidly growing global metabolic problem. Although Saudi Arabia reports one of the highest prevalence levels of obesity and diabetes, a very limited number of epidemiological studies have examined the prevalence of metabolic syndrome. Therefore, the main aim of the current study was to estimate the prevalence of metabolic syndrome and its risk factors among the adult Saudi population in comparison to other countries.

Methods: A total of 12,126 Saudi subjects were randomly recruited from the 13 administrative regions, and evaluated for metabolic syndrome and its risk factors. This exercise was carried out by trained physicians, through clinical evaluations and overnight fasting blood glucose and lipid profile measurements. Both the International Diabetes Federation (IDF) and modified National Cholesterol Education Program and Adult Treatment Panel III (NCEP ATP III) Criteria were employed, and subjects with metabolic syndrome were identified using country-specific waist circumference cutoff values.
\end{abstract}

Results: The prevalence of metabolic syndrome in Saudi Arabia was found to be 39.8\% (34.4\% in men and $29.2 \%$ in women) and $31.6 \%$ (45.0\% in men and $35.4 \%$ in women), according to the NCEP ATP III and IDF criteria, respectively. Metabolic syndrome was also observed to be more prevalent among men and older subjects. The most frequently observed component of metabolic syndrome was found to be low levels of high-density lipoprotein (HDL), followed by abdominal obesity. The most significant risk factors in the studied cohort included age $\geq 45$, smoking history, low educational level, and living in urban areas.

Conclusions: This study shows a high prevalence of metabolic syndrome in Saudi Arabia, and thereby warrants urgent implementation of preventive health care strategies to reduce both morbidity and mortality related to this medical problem.

Keywords: Metabolic syndrome, Prevalence, Risk factors, Obesity, Diabetes, Cross-sectional survey, Saudi Arabia

\section{Background}

Metabolic syndrome was first recognized by the medical community during the late 1980 s and was characterized by the clustering of abdominal obesity, elevated blood pressure, hyperglycemia, and dyslipidemia [1]. This syndrome has been redefined through several amendments by different scientific bodies, and was finally defined by either the ATP III [2] or IDF criteria [3], wherein the

\footnotetext{
* Correspondence: krubeaan@dsrcenter.org

${ }^{1}$ University Diabetes Center, College of Medicine, King Saud University, PO Box 18397, Riyadh, Riyadh 11415, Saudi Arabia

Full list of author information is available at the end of the article
}

IDF criteria mandates the presence of central obesity as one of the components of metabolic syndrome. Subjects with metabolic syndrome are at increased risk for coronary heart disease (CHD), and the presence of metabolic syndrome alone can predict approximately $25 \%$ of all new-onset cardiovascular disease (CVD) [4]. In addition, metabolic syndrome is associated with an increased risk of death from CHD, CVD, and all other causes [5]. It affects nearly one quarter of the adult population worldwide, and its prevalence varies, according to the definition used, ethnicity under study, and level of urbanization [6]. Among the most recent studies, the 
prevalence of metabolic syndrome has been reported to be between $10 \%$ and $84 \%$ worldwide depending on the age, sex, and ethnicity of the population [7]. The National Health and Nutrition Examination Survey (NHANES), using the ATP III criteria, showed the prevalence of metabolic syndrome to be $34.5 \%$, whereas this figure was $39.0 \%$ with the IDF criteria [8]. These findings are different from those observed in an Irish study that reported a prevalence at $21.4 \%$ and $13.2 \%$, using the IDF and ATP III definitions, respectively [9]. The prevalence was even lower among Chinese individuals, reported at $7.9 \%$ and $15.1 \%$ using ATP III and IDF definitions, respectively [10].

The Middle East and North African (MENA) region is known for its high prevalence of metabolic syndrome, where it has been reported to be $45.5 \%$ and $24.3 \%$ in Tunisia, using the IDF criteria and ATP III definition, respectively [11]. Gulf countries, being part of the Middle East, have shown a prevalence of metabolic syndrome that ranges from $17 \%$ in Oman [12] to $40.5 \%$ in the United Arab Emirates (UAE) [13], according to the ATP III and IDF criteria, respectively. Although no recent nationwide survey has evaluated the prevalence of metabolic syndrome in Saudi Arabia, Al-Nozha et al. [14] reported it to be $39.3 \%$ in 2005, using the 2001 ATP III criteria.

This study is a part of the Saudi Abnormal Glucose Metabolism and Diabetes Impact Study (SAUDI-DM) [15] that investigates the prevalence of metabolic syndrome and its risk factors in the adult Saudi society, in comparison to other societies.

\section{Methods \\ Subjects}

The SAUDI-DM is a nationwide, household crosssectional population-based survey that uses a multistage stratified cluster sampling technique. The study recruited 87,417 Saudi nationals between 2007 and 2009 from the 13 administrative regions of Saudi Arabia. The data of all study participants were adjusted for age, area of residency (urban and rural, according to the definitions of the Ministry of Municipal and Rural Affairs), and sex distribution, using the Saudi national census for the year 2007 that led to the exclusion of 34,047 noncompatible participants [15]. For the current analysis, we further excluded 17,172 subjects with incomplete clinical data, or those who did not report for blood sampling. Subjects younger than 18 years of age (totaling $23,523)$ were also excluded. A total of 549 women from this cohort were found to be pregnant and had to be excluded. The final study cohort comprised of 12,126 Saudi subjects aged $\geq 18$ years, with complete clinical and biochemical data, as shown in Fig. 1.

The current study was conducted by trained physicians and nurses, through primary healthcare centers, to secure accurate and complete data. The data that were collected consisted of general demographic and clinical information including age, sex, highest level of education

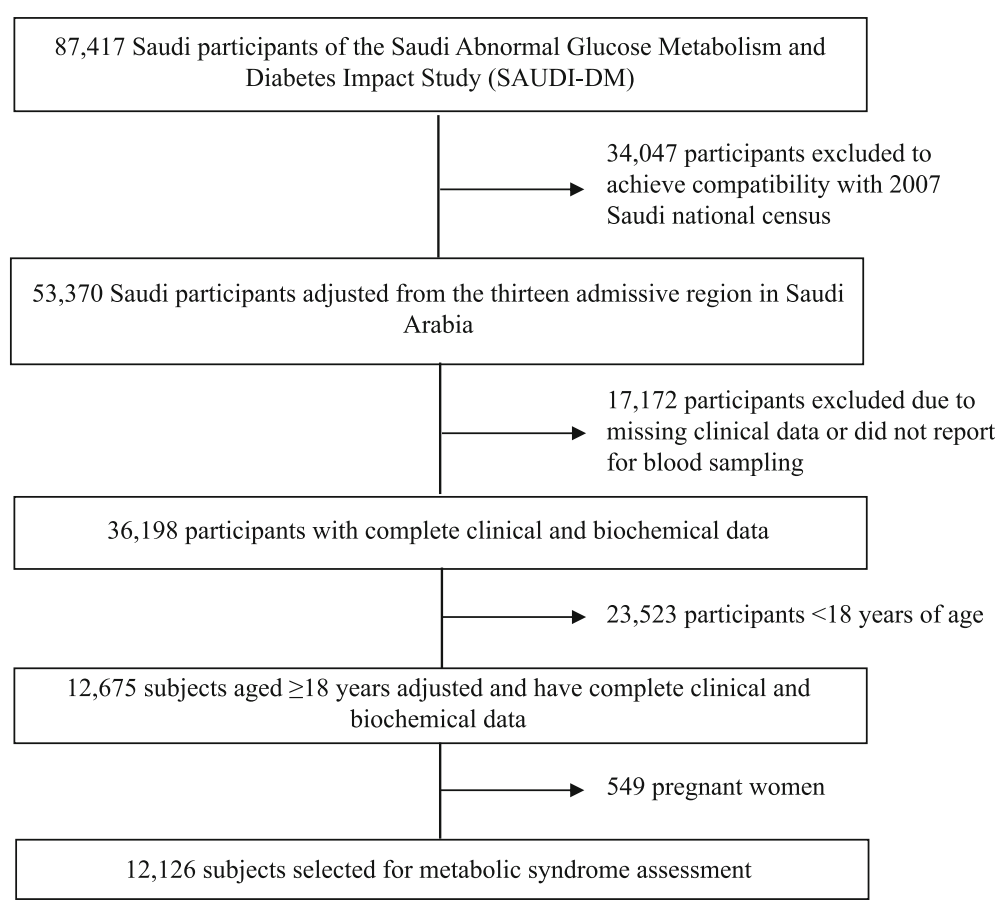

Fig. 1 Flow chart of the study cohort selection 
attained, and monthly income, in addition to history of diabetes, hypertension, and dyslipidemia. The SAUDIDM study was reviewed and approved by the Institutional Review Board at the College of Medicine, King Saud University.

\section{Anthropometric measurements and vital signs}

Anthropometric measurements, including weight, height, and waist circumference, were taken with the subjects in a standing position, wearing light clothing without shoes. Weight and height were assessed, using a weighing scale (Adam Equipment Oxford CT USA, model MDW-250 L) with a capacity of $250 \mathrm{~kg}$ and reliability of $0.1 \mathrm{~kg}$. Waist circumference was measured at the midpoint between the top of the iliac crest and the lower margin of the last palpable rib. Hip circumference was measured at the widest part of the body below the waist. The waist-to-hip ratio (WHR) was calculated by dividing the waist circumference by the hip circumference. Systolic (SBP) and diastolic blood pressure (DBP) measurements were taken from the left arm, after at least $5 \mathrm{~min}$ of rest, with the subjects in a sitting position, using a standardized mercury sphygmomanometer (Baumanometer, Model 0320, W.A. Baum Co., Inc. USA).

\section{Laboratory analysis}

All subjects were asked to report to the nearest primary health care center (PHCC) after more than $10 \mathrm{~h}$ of overnight fasting, after which $10 \mathrm{~mL}$ of venous blood was collected using a sodium fluoride tube. All blood samples were sent to the central laboratory at the Strategic Center for Diabetes Research in the Riyadh, the capital city of the Kingdom, using portable refrigerators in which the temperature was maintained between $4{ }^{\circ} \mathrm{C}$ and $8{ }^{\circ} \mathrm{C}$. Plasma was stored at $-20^{\circ} \mathrm{C}$ at the central laboratory. The blood glucose assessment was conducted, using the glucose oxidase/peroxidase method; whereas blood cholesterol was measured using the esterase oxidase/peroxidase method; and levels of high-density lipoprotein (HDL), low-density lipoprotein (LDL), and triglycerides were determined, using the glycerokinase oxidase/peroxidase method.

\section{Definition of metabolic syndrome}

Metabolic syndrome was defined, using both the modified National Cholesterol Program Adult Treatment Panel III (NCEP ATP III) and the International Diabetes Federation (IDF) criteria, and implementing the new cutoff value for waist circumference in Saudi society [16]. Therefore, subjects were considered to have metabolic syndrome if they had central obesity that was defined by a waist circumference $\geq 92 \mathrm{~cm}$ in men and $\geq 87 \mathrm{~cm}$ in women, along with two or more of the following criteria, as per the IDF definition [3]: high fasting glucose level $\geq 100 \mathrm{mg} / \mathrm{dL}(5.6 \mathrm{mmol} / \mathrm{L})$, or patients known to have diabetes mellitus and/or on treatment for diabetes; hypertriglyceridemia - serum triglyceride level $\geq$ $150 \mathrm{mg} / \mathrm{dL}(1.7 \mathrm{mmol} / \mathrm{L})$; low HDL cholesterol - serum HDL cholesterol $<40 \mathrm{mg} / \mathrm{dL}(1.0 \mathrm{mmol} / \mathrm{L})$ in men and $<50 \mathrm{mg} / \mathrm{dL}(1.3 \mathrm{mmol} / \mathrm{L})$ in women, or patients known to have dyslipidiema; high blood pressure - SBP $\geq$ $130 \mathrm{mmHg}$ and/or DBP $\geq 85 \mathrm{mmHg}$, or patients known to have hypertension, and/or on treatment for hypertension. The NCEP-APT III criteria for metabolic syndrome were met if an individual had three or more of the aforementioned criteria [4].

\section{Statistical analysis}

Data were analyzed using the SPSS statistical package version 21. Continuous variables were expressed as mean \pm standard deviation (SD), and categorical variables were expressed as percentages. The $t$ - test was used for continuous variables and chi-squared test for categorical variables. Risk factors for metabolic syndrome were assessed using univariate, age- and sex-adjusted, and multivariate logistic regression models. The odds ratio and $95 \%$ confidence intervals were used to express different risk factors. A $p$-value less than 0.05 was used as the level of significance.

\section{Results}

The studied cohort of 12,126 subjects represents the Saudi population over 10-year age intervals, with a mean age of $35.7 \pm 15.0$ years, wherein men were significantly older than women, and both had similar distribution. More subjects lived in urban areas than in rural areas. The prevalence of obesity, particularly as morbid obesity (body mass index (BMI) $\geq 30 \mathrm{~kg} / \mathrm{m} 2$ ), was higher among women versus men [ $(36.5 \%$ versus $29.4 \%(p<0.001)]$. Men had a significantly higher mean waist circumference; whereas women had a higher mean hip circumference. The mean WHR was significantly higher among men. Only $20.7 \%$ of the study cohort had a relatively high monthly income (> 8000 Saudi Riyals [SR]) and a higher proportion of men were smokers in comparison to women. Men had a significantly higher mean SBP and DBP, as well as higher mean fasting plasma glucose (FPG), mean LDL, and triglycerides. In contrast, mean HDL cholesterol was significantly higher among women. The prevalence of metabolic syndrome according to the IDF criteria was $31.6 \%$; specifically, $34.4 \%$ in men and $29.2 \%$ in women. However, according to the ATP III criteria, the prevalence of metabolic syndrome was higher at $39.9 \%$; specifically, $45.0 \%$ in men and $35.4 \%$ in women, as shown in Table 1.

The prevalence of metabolic syndrome and its components increased with age, except in the age group $\geq 70$ years. The most frequently observed component of 
Table 1 Baseline characteristics of the study cohort and the calculated metabolic syndrome prevalence

\begin{tabular}{|c|c|c|c|c|}
\hline $\begin{array}{l}\text { Total } \\
12,126\end{array}$ & $\begin{array}{l}\text { Men } \\
5571(45.94)\end{array}$ & & $\begin{array}{l}\text { Women } \\
6555(54.06)\end{array}$ & $P$ value \\
\hline \multicolumn{5}{|l|}{ Discreptive analysis; mean ( \pm SD) } \\
\hline Mean age (years) & $35.7( \pm 15.0)$ & $36.1( \pm 15.2)$ & $35.5( \pm 14.8)$ & $P$ value \\
\hline Mean WC (cm) & $87.0( \pm 16.7)$ & $89.71 \pm 17.11$ & $84.75 \pm 16.03$ & 0.035 \\
\hline Mean Hip (cm) & $99.1( \pm 16.8)$ & $98.7( \pm 16.8)$ & $99.4( \pm 16.8)$ & $<0.001$ \\
\hline Mean $\mathrm{W}-\mathrm{H}$ ratio & $0.9( \pm 0.12)$ & $0.9( \pm 0.1)$ & $0.9( \pm 0.1)$ & 0.014 \\
\hline Mean Systolic Bp (mmHg) & $117.7( \pm 13.8)$ & $119.7( \pm 13.1)$ & $116.0( \pm 14.1)$ & $<0.001$ \\
\hline Mean Diastolic Bp (mmHg) & $76.1( \pm 8.6)$ & $77.3( \pm 8.9)$ & $75.2( \pm 8.7)$ & $<0.001$ \\
\hline Mean FPG (mmol/L) & $5.7( \pm 2.4)$ & $5.8( \pm 2.6)$ & $5.6( \pm 2.3)$ & $<0.001$ \\
\hline Mean LDL Cholesterol (mmol/L) & $3.2( \pm 1.1)$ & $3.2( \pm 1.1)$ & $3.2( \pm 1.0)$ & $<0.001$ \\
\hline Mean triglyceride (mmol/L) & $1.6( \pm 1.2)$ & $1.8( \pm 1.3)$ & $1.5( \pm 0.1)$ & 0.012 \\
\hline Mean HDL cholesterol (mmol/L) & $0.1( \pm 0.3)$ & $0.9( \pm 0.3)$ & $1.0( \pm 0.3)$ & $<0.001$ \\
\hline \multicolumn{5}{|l|}{ Frequancy anlysis; number (\%) } \\
\hline Age groups: $18-29$ years & $5196(42.9)$ & $2328(41.8)$ & $2868(43.8)$ & $<0.001$ \\
\hline 30-39 years & $2660(21.9)$ & $1276(22.9)$ & 1384(21.1) & \\
\hline $40-49$ years & $2207(18.2)$ & $942(16.9)$ & $1265(19.3)$ & \\
\hline $50-59$ years & $1086(8.1)$ & $524(9.4)$ & $562(8.6)$ & \\
\hline 60-69 years & $573(4.7)$ & $315(5.7)$ & 258(3.9) & \\
\hline$\geq 70$ years & 404(3.3) & 186(3.3) & 218(3.3) & \\
\hline BMl groups $<18.5$ & 673(5.6) & $315(5.7)$ & $358(5.5)$ & $<0.001$ \\
\hline $18.5-24.9$ & $3783(31.2)$ & 1807(32.4) & 1976(30.1) & \\
\hline $25-29.9$ & $3642(30.0)$ & $1812(32.5)$ & 1830(27.9) & \\
\hline$\geq 30$ & $4028(33.2)$ & $1637(29.4)$ & $2391(36.5)$ & \\
\hline Monthly Income < 4000 SR & $5255(43.3)$ & 2175(39.0) & $3080(46.1)$ & $<0.001$ \\
\hline $4000-8000$ SR & 4438(36.6) & 2173(39.0) & 2265(34.6) & \\
\hline$>8000 \mathrm{SR}$ & $2433(20.1)$ & $1223(21.95)$ & $1210(18.46)$ & \\
\hline Smoking & $1564(12.9)$ & $1475(26.5)$ & $89(1.4)$ & $<0.001$ \\
\hline Educational level: Illiterate & 2417(19.9) & $554(9.94)$ & $1863(28.42)$ & \\
\hline Less than high school & $3648(30.1)$ & 1855(33.3) & 1793(27.4) & \\
\hline More than or equal high school & $6061(49.1)$ & $3162(56.8)$ & 2899(44.2) & \\
\hline Family history of: Diabetes Mellitus & $6200(51.1)$ & 2896(51.1) & $3304(50.4)$ & 0.083 \\
\hline Hypertension & $4212(34.7)$ & 1887(33.9) & 2325(35.5) & 0.066 \\
\hline \multicolumn{5}{|l|}{ Metabolic Syndrome Prevalence } \\
\hline IDF criteria (WC $+\geq 2$ risk factors) & $3833(31.6)$ & 1917(34.4) & 1916(29.2) & $<0.001$ \\
\hline NCEP-ATP-III criteria (3 or more risk factors) & 4828(39.8) & $2507(45.0)$ & 2321(35.4) & $<0.001$ \\
\hline
\end{tabular}

NCEP-ATP-III; National Cholesterol Education Program and Adult Treatment Panel III, HDL; high density lipoprotein, IDF; International Diabetes Federation, LDL; low density lipoprotein, WC; waist circumference, WHR; waist-to-hip ratio

metabolic syndrome was low HDL that affected around $80 \%$ of the sample. Abdominal obesity ranged between $25 \%$ and $70 \%$, whereas elevated blood glucose affected $25 \%$ to $60 \%$ according to the age group. Elevated triglycerides and high blood pressure were the components of metabolic syndrome that occurred least frequently.

Both male and female subjects showed an increasing prevalence of metabolic syndrome with age, although this was more pronounced according to the ATP III criteria. Men had a higher prevalence of metabolic syndrome compared to women in the younger age groups; whereas women had a higher prevalence in the age group $\geq 70$ years. Middle-aged men and women had an almost similar prevalence of metabolic syndrome. Women in different age groups showed a high prevalence of low HDL and abdominal obesity, whereas the prevalence of elevated blood pressure, blood glucose, and triglycerides was higher among men as compared to 
women in 10-year age intervals, as shown in Table 2. Figure 2 shows the frequency of one or more components of metabolic syndrome, according to differences in age and sex distribution. As the number of metabolic syndrome components increase, the relative frequency is reduced, regardless of age group or sex. The frequency of three or more components of metabolic syndrome increased with age in both male and female subjects. In addition, the frequency of three or more risk factors for metabolic syndrome was found to be higher among men than women, with the exception of the $>70$ age group, in which women had a higher frequency than men.

\section{Risk factors}

When the risk factors for metabolic syndrome were assessed in the current study, any age $\geq 45$ years was the most important and significant risk factor in both unadjusted and multivariate models. The male gender, smoking, and increased BMI were each independently and significantly associated with an increased risk of metabolic syndrome. Higher monthly income and low educational level were found to be significant risk factors for metabolic syndrome, when the unadjusted model was used. However, high monthly income remained significant only in the age- and sex-adjusted model, and low educational level remained independently significant only in the multivariate adjusted model. Living in an urban area was significantly associated with an increased risk of metabolic syndrome in the age- and sex- or multivariate adjusted models. Family history of DM and hypertension were also associated with an increased risk of metabolic syndrome after adjusting for age and sex, whereas only family history of hypertension remained significant in the multivariate adjusted model, as shown in Table 3.

\section{Discussion}

Saudi Arabia is known to be one of the top countries worldwide with a high prevalence of diabetes, and similarly high rate of obesity that has a direct effect on more than one third of its adult population [17]. In addition, the prevalence of other components of metabolic syndrome is reaching soaring heights in the Kingdom [14]. Therefore, with such a high prevalence of the various components of metabolic syndrome, the prevalence of metabolic syndrome in Saudi Arabia would be expected to exceed that is reported in other countries. The current study shows the prevalence of metabolic

Table 2 Prevalence of metabolic syndrome $(95 \% \mathrm{Cl})$ and its components according to age and sex strata

\begin{tabular}{|c|c|c|c|c|c|c|c|}
\hline \multirow{2}{*}{$\begin{array}{l}\text { Age } \\
\text { groups }\end{array}$} & \multirow{2}{*}{$\begin{array}{l}\text { Abdominal } \\
\text { obesity }\end{array}$} & \multirow{2}{*}{$\begin{array}{l}\text { Elevated blood } \\
\text { pressure }\end{array}$} & \multirow{2}{*}{$\begin{array}{l}\text { Elevated blood } \\
\text { glucose }\end{array}$} & \multirow{2}{*}{$\begin{array}{l}\text { Elevated } \\
\text { triglycerides }\end{array}$} & \multirow{2}{*}{$\begin{array}{l}\text { Low HDL } \\
\text { cholesterol }\end{array}$} & \multicolumn{2}{|c|}{ Metabolic syndrome } \\
\hline & & & & & & IDF & NCEP-ATP III \\
\hline \multicolumn{8}{|l|}{ Total } \\
\hline $18-29$ years & $25.3(24.1-26.5)$ & $12.0(11.2-12.9)$ & $25.0(23.8-26.2)$ & $22.0(20.85-23.11)$ & $75.7(74.5-76.9)$ & $13.4(12.4-14.3)$ & 19.6(18.5-20.7) \\
\hline 30-39 years & $51.4(49.5-53.3)$ & $24.7(23.0-26.3)$ & $34.6(32.7-36.4)$ & $38.83(37.0-40.7)$ & 80.2(78.6-81.7) & 33.8(31.96-35.6) & $42.7(40.8-44.6)$ \\
\hline 40-49 years & $66.3(64.3-68.3)$ & $38.6(36.5-40.6)$ & $46.8(44.7-48.8)$ & 41.55(39.5-43.6) & 81.4(79.8-83.0) & 49.4(47.3-51.5) & $57.9(55.8-59.9)$ \\
\hline $50-59$ years & 70.4(67.7-73.2) & $53.31(50.3-56.3)$ & $56.5(53.6-59.5)$ & $42.4(39.4-45.3)$ & 82.2(79.96-84.5) & $56.3(53.3-49.2)$ & 66.8(64.0-69.6) \\
\hline $60-69$ years & $69.8(66.1-73.5)$ & $63.4(59.4-67.3)$ & $59.9(55.9-63.9)$ & 44.0(39.9-48.0) & 79.8(76.5-83.1) & $58.5(54.4-62.5)$ & $71.0(67.3-74.7)$ \\
\hline$\geq 70$ years & 59.7(54.9-64.4) & $66.8(62.2-71.4)$ & $57.7(52.9-62.5)$ & $38.4(33.6-43.1)$ & 78.7(74.7-82.7) & $50.7(45.9-55.6)$ & $65.8(61.2-70.5)$ \\
\hline \multicolumn{8}{|l|}{ Men } \\
\hline $18-29$ years & $27.7(25.9-29.5)$ & $16.5(15.0-18.0)$ & $28.4(26.6-30.3)$ & $28.4(26.6-30.2)$ & $71.0(69.2-72.9)$ & 16.4(14.9-17.9) & $24.4(22.7-26.2)$ \\
\hline $30-39$ years & $52.4(49.6-55.1)$ & $30.4(27.9-32.9)$ & $41.4(38.7-44.1)$ & 49.61(49.9-52.4) & 77.6(75.3-79.9) & $39.26(36.7-41.94)$ & $51.7(49.0-54.5)$ \\
\hline $40-49$ years & $63.1(60.0-66.1)$ & $41.2(38.1-44.3)$ & $49.2(46.0-52.3)$ & $51.1(47.9-54.3)$ & $77.3(74.6-80.0)$ & 49.5(46.3-52.7) & $60.3(57.2-63.4)$ \\
\hline $50-59$ years & 68.9(64.9-72.9) & $58.2(54.0-62.4)$ & $57.4(53.2-61.7)$ & 49.6(45.3-53.9) & 79.8(76.3-83.2) & $57.25(53.0-61.5)$ & 70.8(66.9-74.7) \\
\hline $60-69$ years & $69.2(64.1-74.3)$ & $61.9(56.5-67.3)$ & $58.7(53.3-64.2)$ & $47.0(41.5-52.5)$ & $75.2(70.5-80.0)$ & 58.7(53.3-64.2) & $71.11(66.1-76.1)$ \\
\hline$\geq 70$ years & $55.9(48.8-63.1)$ & 66.7(59.9-73.4) & $59.7(52.6-66.7)$ & 43.0(35.9-50.1) & 69.4(62.7-76.0) & $45.2(38.0-52.3)$ & 61.8(54.9-68.8) \\
\hline \multicolumn{8}{|l|}{ Women } \\
\hline $18-29$ years & $23.3(21.7-24.8)$ & $8.40(7.38-9.42)$ & $22.18(20.7-23.7)$ & $16.77(15.4-18.1)$ & 79.53(78.1-81.0) & 10.9(9.8-12.1) & 15.7(14.3-17.0) \\
\hline 30-39 years & 50.5(47.9-53.1) & 19.4(17.3-21.4) & 28.3(25.9-30.6) & $28.9(26.5-31.3)$ & $82.5(80.5-84.5)$ & $28.7(26.3-31.5$ & 34.3(31.8-36.8) \\
\hline $40-49$ years & $68.7(66.1-71.3)$ & $36.6(34.0-39.3)$ & $45.0(42.2-47.7)$ & $34.5(31.9-37.1)$ & $84.5(82.5-86.5)$ & $49.3(46.6-52.1)$ & 56.1(53.3-58.8) \\
\hline 50-59 years & $71.9(68.2-75.6)$ & $48.8(44.6-52.9)$ & $55.7(51.6-58.8)$ & 35.6(31.6-39.6) & $84.5(81.5-87.5)$ & $55.3(51.2-59.5)$ & $63.0(59.0-67.0)$ \\
\hline 60-69 years & $70.5(65.0-76.1)$ & 65.1(59.3-70.9) & $61.2(55.3-67.2)$ & $40.3(34.3-46.3)$ & 85.3(81.0-89.6) & $58.1(52.1-64.2)$ & $70.9(65.4-76.5)$ \\
\hline$\geq 70$ years & $62.8(56.4-69.3)$ & $67.0(60.7-73.2)$ & $56.0(49.4-62.6)$ & $34.4(28.1-40.7)$ & $86.7(82.2-91.2)$ & 55.5(48.9-62.1) & $69.27(63.15-75.39)$ \\
\hline
\end{tabular}




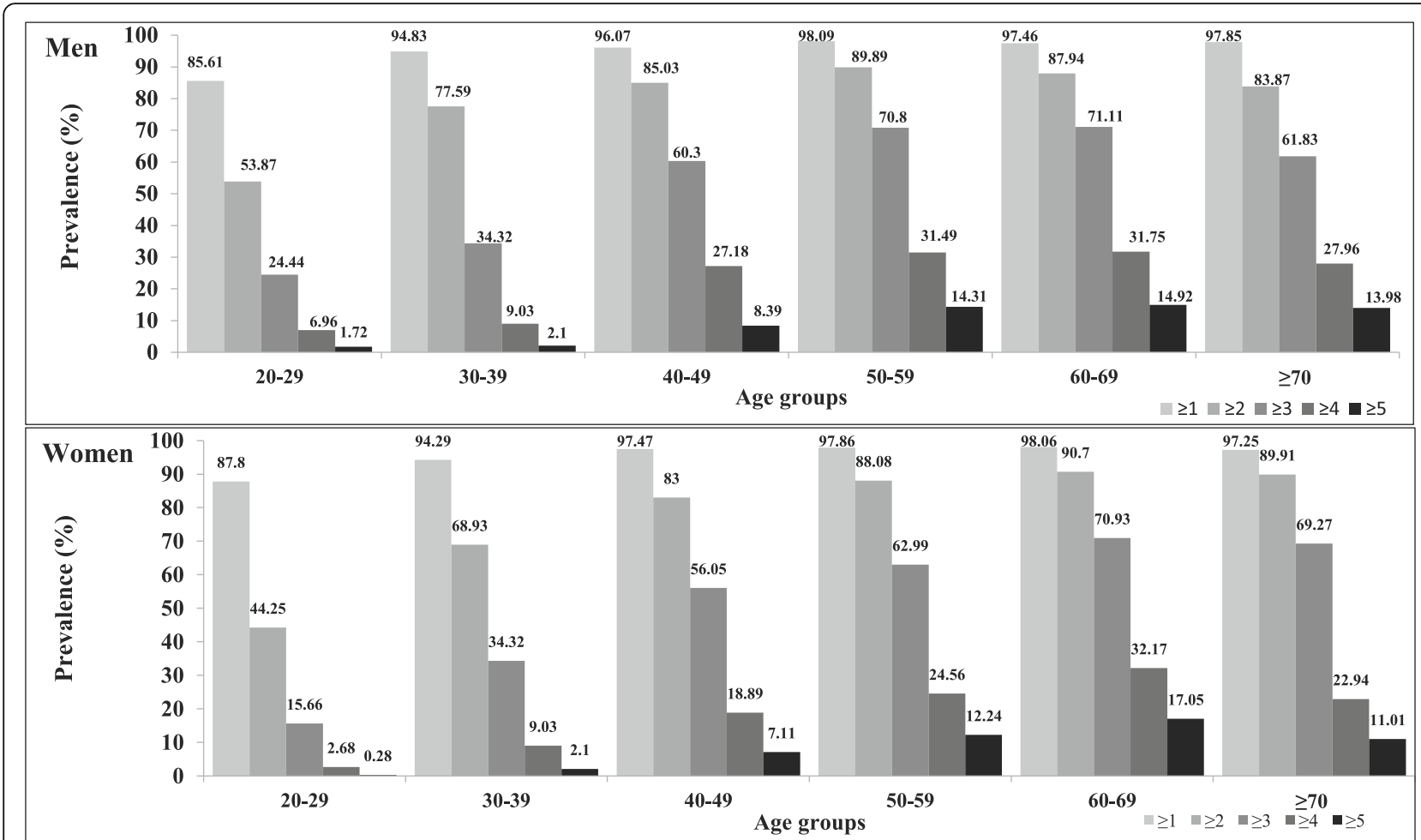

Fig. 2 Relative frequency of one or more components of metabolic syndrome, according to different ages and sex distribution

syndrome in Saudi Arabia to be $39.8 \%$ according to the ATP III criteria and 31.6\% according to the IDF criteria, when local waist circumference cutoff values have been implemented [16]. Gulf countries that have passed through similar socio-economic transitions have also shown similar levels of prevalence of metabolic syndrome, in spite of the use of lower cutoff values for waist circumference in both men and women in the current study [18-20]. The prevalence of metabolic syndrome in these countries ranged from $33.7 \%$ [21] to $40.5 \%$ according to the IDF criteria [13], and from $17 \%$ [12] to $39.6 \%$ [11] according to the ATP III criteria. The prevalence of metabolic syndrome reported in other MENA countries show a comparatively lower prevalence. The prevalence in Iran was reportedly $32.1 \%$ and $33.2 \%$ in 2006 , according to the IDF and ATP III criteria, respectively [22]; and that in Tunisia it was $30.0 \%$ according to the ATP III criteria [23].

These findings indicate that in terms of the prevalence of metabolic syndrome, Saudi Arabia is one of the leading MENA countries. The prevalence of metabolic syndrome among the Saudi population is also higher than that reported among ethnicities, such as the adult Spanish [24] and Australian [25] populations, in which the prevalence is reported as $31.0 \%$ for Spaniards and $30.7 \%$ for Australians, according to the ATP III and IDF

Table 3 Risk factors for metabolic syndrome odds ratio (95\% Cl) assessment with sex and gender and multivariate adjustment

\begin{tabular}{llll}
\hline Number of components factors & $\begin{array}{l}\text { Unadjusted } \\
\text { OR }(95 \% \mathrm{Cl})\end{array}$ & $\begin{array}{l}\text { Age and sex Adjusted } \\
\text { OR }(95 \% \mathrm{Cl})\end{array}$ & $\begin{array}{l}\text { Multivariate } \\
\text { OR (95\% Cl) }\end{array}$ \\
\hline Age $\geq 45$ years & $4.4(4.0-4.8)$ & - & $3.9(3.4-4.5)$ \\
Male gender & $1.5(1.39-1.60)$ & - & $2.0(1.8-2.3)$ \\
Smoking & $1.6(1.4-1.8)$ & $1.2(1.0-1.4)$ & $1.4(1.1-1.6)$ \\
High monthly income & $1.1(1.0-1.2)$ & $1.2(1.1-1.3)$ & $1.1(1.0-1.2)$ \\
Low educational level & $1.5(1.4-1.7)$ & $1.1(1.0-1.2)$ & $1.3(1.1-1.5)$ \\
Urban residency & $1.0(1.0-1.1)$ & $1.2(1.0-1.2)$ & $1.1(1.0-1.3)$ \\
Body mass index & $1.6(1.1-1.2)$ & $1.1(1.13-1.15)$ & $1.2(1.1-1.2)$ \\
Family history of diabetes mellitus & $1.0(1.0-1.1)$ & $1.3(1.2-1.4)$ & $1.0(0.9-1.1)$ \\
Family history of hypertension & $1.0(1.0-1.1)$ & $1.3(1.2-1.4)$ & $1.2(1.1-1.4)$ \\
\hline
\end{tabular}


criteria, respectively. In addition, the prevalence of metabolic syndrome in the Saudi population, according to the revised ATP III criteria, was higher than that reported in Korea and South Asia [26, 27], despite of the use of lower Asian-specific cutoff values for abdominal obesity of $90 \mathrm{~cm}$ and $80 \mathrm{~cm}$ for men and women, respectively.

The current study shows that men were more frequently affected by metabolic syndrome than women, based on both sets of criteria. These findings are inconsistent with those reported among the Caucasian ethnicity [28]. The male predominance observed in the current study could be explained by the higher frequency of diabetes, hypertension, hypertriglyceridemia, and smoking among men in Saudi society, as compared to other ethnicities [15, 29-31]. Furthermore, the waist circumference cutoff values that were used for men in the community under study were lower than those proposed by the ATP III and IDF [2, 3]. However, this was not the case for women, as the waist circumference cutoff values used for Saudi women were higher than those specified by the IDF criteria, and closer to those of the ATP III criteria [16]. Another reason behind the low prevalence of metabolic syndrome among women in Saudi society is the lower rate of smoking among Saudi women. This protects them from the negative effects of tobacco smoking on the emergence of several metabolic disorders, including the more serious insulin resistance, hyperinsulinemia, and increased waist circumference [32].

Women in this cohort, older than 70 years of age, had a higher prevalence of metabolic syndrome than men. This could be explained on one hand by the postmenopausal estrogen withdrawal effect that increases the prevalence of chronic diseases [33], and on the other hand by the poor survival observed among men with metabolic syndrome at a younger age. In addition, this study highlighted the fact that being male was a significant and independent risk factor for metabolic syndrome, until the age of 70 years.

Similar to the observations reported in the NHANES study [34], the prevalence of metabolic syndrome in the current study increased with age, reaching its peak in the sixth and the seventh decades, and decreased thereafter. This might be because age is associated with hormonal alterations, increased visceral obesity, and insulin resistance [35]. Another explanation for such age-dependent increases in the prevalence of metabolic syndrome is the parallel increase in the prevalence of the distinct components of metabolic syndrome, mainly diabetes and hypertension, with age in the Saudi population $[15,29]$. In addition, the current study shows that age is a significant and independent risk factor for metabolic syndrome.
Low HDL cholesterol was the most frequent component of metabolic syndrome observed in the current study, and this finding has also been reported in other population-based studies in South Asia [26] and the Middle East [22, 36]. Low HDL cholesterol was observed more frequently in women; a finding that is consistent with most of the other studies conducted among different ethnicities [22, 36]. This observation could be explained by the higher rate of abdominal obesity observed among women in the current study, a factor that is known to lower HDL values [37]. In the present cohort, $43.4 \%$ of the participants had more than two risk factors for metabolic syndrome, a number that is higher than that observed among Omanis [38], but lower than that observed among Kuwaitis [36]. These subjects represent a high-risk group for the development of metabolic syndrome. This warrants early intervention to prevent the progression of this very expensive and even lifethreatening syndrome, by adopting alternative measures that include lifestyle modifications.

Living in urban areas and a lower education level were significant risk factors for metabolic syndrome in Saudi society, a finding that is similar to those observed in other ethnicities [39-41]. This significant association is expected, because urbanization is associated with an increased prevalence of cardiovascular risk factors, such as hypertension, obesity, and dyslipidemia, as it offers economic improvement to the rural population and exposes them to additional health risks, including a poor diet and sedentary lifestyle [40, 41]. Such effects of urbanization are obvious in populations that have experienced rapid urbanization and swift lifestyle changes, such as those in Saudi Arabia and other Gulf countries [42]. The significant association between a low educational level and metabolic syndrome could be mediated by other risk factors, such as smoking and high carbohydrate intake [23].

No significant effect of a high monthly income on metabolic syndrome was noted in the current study. This finding was unexpected and differed from previous reports of other Gulf countries; however, it is in line with the inconsistency observed in the reported relationship between a high-income status and the development of metabolic syndrome [7, 20].

The current study gains its strength from the fact that it was a nationwide study with a large number of participants. Another strength of the current study was the use of a clear case definition that was based on diagnostic confirmation, using blood tests to identify diabetic and dyslipidemic cases, and country-specific waist circumference cutoff values. However, the study was limited by the fact that it was a cross-sectional study; thus, the causal relationship between metabolic syndrome and certain risk factors could not be elicited. The study was 
also compromised by the exclusion of physical activity and dietary assessments, both of which are important contributing factors for metabolic syndrome.

\section{Conclusions}

In conclusion, this study places Saudi Arabia as one of the countries with the highest prevalence of metabolic syndrome. Although the risk factors for metabolic syndrome in Saudi society were similar to those reported internationally, men were particularly at a greater risk of having metabolic syndrome. A high income had no effect on the prevalence of metabolic syndrome; thus, any prevention program should not consider income as a selection factor.

These findings are startling and should alert policy makers in Saudi Arabia to consider the implementation of preventive lifestyle interventions that include smoking cessation and weight control programs. Furthermore, in order to prevent metabolic syndrome, policy makers should consider the promotion of a healthy diet and physical activity in the planning of future health care strategies in Saudi Arabia.

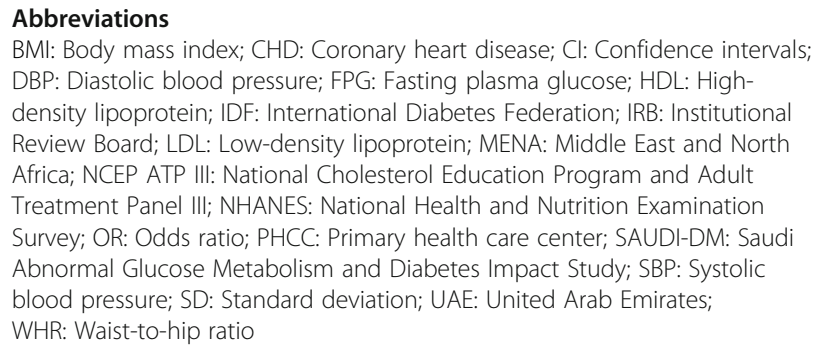

BMI: Body mass index; CHD: Coronary heart disease; Cl: Confidence intervals; DBP: Diastolic blood pressure; FPG: Fasting plasma glucose; HDL: Highdensity lipoprotein; IDF: International Diabetes Federation; IRB: Institutional Review Board; LDL: Low-density lipoprotein; MENA: Middle East and North Africa; NCEP ATP III: National Cholesterol Education Program and Adult Treatment Panel III; NHANES: National Health and Nutrition Examination Survey; OR: Odds ratio; PHCC: Primary health care center; SAUDI-DM: Saudi Abnormal Glucose Metabolism and Diabetes Impact Study; SBP: Systolic blood pressure; SD: Standard deviation; UAE: United Arab Emirates; WHR: Waist-to-hip ratio

\section{Acknowledgments}

The authors thank the professionals of the centers that assisted in data collection and all the participating patients.

\section{Funding}

This study was funded by the University Diabetes Center at King Saud University, Ministry of Health, and the Tawuniya Company for health insurance.

\section{Availability of data and materials}

The datasets used and/or analyzed during the current study are available from the corresponding author on reasonable request.

\section{Authors' contributions}

$K A, Y A, N B$, and $A M Y$ designed the study, wrote the manuscript, designed figures, interpreted data, and critically revised the article. AAA HMA, BA, FIA, KAN, KAS researched data, wrote the manuscript, and critically revised the article. All authors read and approved the final manuscript

\section{Ethics approval and consent to participate}

The study protocol was submitted to, and approved by the Institutional Review Board, at the College of Medicine, King Saud University. This research was conducted in accordance with the Declaration of Helsinki and a written consent form was obtained from each participant.

\section{Consent for publication}

Not applicable.

\section{Competing interests}

The authors declare that they have no competing interests.

\section{Publisher's Note}

Springer Nature remains neutral with regard to jurisdictional claims in published maps and institutional affiliations.

\section{Author details}

${ }^{1}$ University Diabetes Center, College of Medicine, King Saud University, PO Box 18397, Riyadh, Riyadh 11415, Saudi Arabia. ${ }^{2}$ Nutrition Department, University Diabetes Center, King Saud University, Riyadh, Saudi Arabia. ${ }^{3}$ Registry Department, University Diabetes Center, King Saud University, Riyadh, Saudi Arabia. ${ }^{4}$ College of Medicine, King Saud University, Riyadh, Saudi Arabia.

Received: 25 April 2017 Accepted: 27 February 2018

Published online: 05 March 2018

\section{References}

1. Reaven GM. Role of insulin resistance in human disease. Diabetes. 1988;37: 1595-607.

2. Grundy SM, Cleeman II, Daniels SR, Donato KA, Eckel RH, Franklin BA, et al. Diagnosis and management of the metabolic syndrome: an American Heart Association/National Heart, Lung, and Blood Institute scientific statement. Circulation. 2005;112:2735-52.

3. Alberti KGMM, Zimmet P, Shaw J. IDF epidemiology task force consensus group. The metabolic syndrome-a new worldwide definition. Lancet. 2005; 366:1059-62.

4. Grundy SM, Brewer HB Jr, Cleeman JI, Smith SC Jr, Lenfant C. National Heart Lung, and Blood Institute; American Heart Association. Definition of metabolic syndrome: report of the National Heart, Lung, and Blood Institute/American Heart Association conference on scientific issues related to definition. Arterioscler Thromb Vasc Biol. 2004;24:e13-8.

5. Malik S, Wong ND, Franklin SS, Kamath TV, L'Italien GJ, Pio JR, et al. Impact of the metabolic syndrome on mortality from coronary heart disease, cardiovascular disease, and all causes in United States adults. Circulation. 2004; 110:1245-50.

6. International Diabetes Federation: IDF Worldwide Definition of the Metabolic Syndrome. http://www.idf.org/metabolic-syndrome Accessed 13 Feb 2017.

7. Kaur J. A comprehensive review on metabolic syndrome. Cardiol Res Pract. 2014; https://doi.org/10.1155/2014/943162.

8. Ford ES. Prevalence of the metabolic syndrome defined by the international diabetes federation among adults in the U.S. Diabetes Care. 2005;28:2745-9.

9. Waterhouse DF, McLaughlin AM, Sheehan F, O'Shea D. An examination of the prevalence of IDF- and ATPIII-defined metabolic syndrome in an Irish screening population. Ir J Med Sci. 2009;178:161-6.

10. Zhao Y, Yan H, Yang R, Li Q, Dang S, Wang Y. Prevalence and determinants of metabolic syndrome among adults in a rural area of Northwest China. PLoS One. 2014:9:e91578.

11. Bouguerra R, Alberti H, Smida H, Salem LB, Rayana CB, El Atti J, et al. Waist circumference cut-off points for identification of abdominal obesity among the Tunisian adult population. Diabetes Obes Metab. 2007:9:859-68.

12. Al-Lawati JA, Mohammed AJ, Al-Hinai HQ, Jousilahti P. Prevalence of the metabolic syndrome among Omani adults. Diabetes Care. 2003;26:1781-5.

13. Malik M, Razig SA. The prevalence of the metabolic syndrome among the multiethnic population of the United Arab Emirates: a report of a national survey. Metab Syndr Relat Disord. 2008;6:177-86.

14. Al-Nozha M, Al-Khadra A, Arafah MR, Al-Maatouq MA, Khalil MZ, Khan NB, et al. Metabolic syndrome in Saudi Arabia. Saudi Med J. 2005;26:1918-25.

15. Al-Rubeaan K, Al-Manaa H, Khoja T, Ahmad N, Al-Sharqawi A, Siddiqui K, et al. The Saudi abnormal glucose metabolism and diabetes impact study (SAUDI-DM). Ann Saudi Med. 2014;34:465-75.

16. Al-Rubean K, Youssef AM, AlFarsi Y, Al-Sharqawi AH, Bawazeer N, AlOtaibi MT, et al. Anthropometric cutoff values for predicting metabolic syndrome in a Saudi community: from the SAUDI-DM study. Ann Saudi Med. 2017;37: 21-30.

17. Al-Nozha MM, Al-Mazrou YY, Al-Maatoug MA, Arafah MR, Khalil MZ, Khan NB, et al. Obesity in Saudi Arabia. Saudi Med J. 2005;26:824-9. 
18. Khader Y, Bateiha A, El-Khateeb M, Al-Shaikh A, Ajlouni K. High prevalence of the metabolic syndrome among northern Jordanians. J Diabetes Complicat. 2007;21:214-9.

19. Al-Shaibani H, El-Batish M, Sorkhou I, Al-Shamali N, Al-Namash H, Habiba S, et al. Prevalence of insulin resistance syndrome in a primary health care center in Kuwait. Fam Med. 2004;36:540.

20. Mabry RM, Reeves MM, Eakin EG, Owen N. Gender differences in prevalence of the metabolic syndrome in gulf cooperation council countries: a systematic review. Diabet Med. 2010;27:593-7.

21. Bener A, Zirie M, Musallam M, Khader YS, Al-Hamaq AOAA. Prevalence of metabolic syndrome according to adult treatment panel III and international diabetes federation criteria: a population-based study. Metab Syndr Relat Disord. 2009;7:221-9.

22. Zabetian A, Hadaegh F, Azizi F. Prevalence of metabolic syndrome in Iranian adult population, concordance between the IDF with the ATPIII and the WHO definitions. Diabetes Res Clin Pract. 2007;77:251-7.

23. Belfki $\mathrm{H}$, Ben Ali $\mathrm{S}$, Aounallah-Skhiri $\mathrm{H}$, Traissac $\mathrm{P}$, Bougatef $\mathrm{S}$, Maire $\mathrm{B}$, et al. Prevalence and determinants of the metabolic syndrome among Tunisian adults: results of the transition and health impact in North Africa (TAHINA) project. Public Health Nutr. 2013;16:582-90.

24. Fernández-Bergés D, Cabrera de León A, Sanz H, Elosua R, Guembe MJ, Alzamora $\mathrm{M}$, et al. Metabolic syndrome in Spain: prevalence and coronary risk associated with harmonized definition and WHO proposal. DARIOS study. Rev Esp Cardiol (Engl Ed). 2012;65:241-8.

25. Cameron AJ, Magliano DJ, Zimmet PZ, Welborn T, Shaw JE. The metabolic syndrome in Australia: prevalence using four definitions. Diabetes Res Clin Pract. 2007;77:471-8.

26. Aryal N, Wasti SP. The prevalence of metabolic syndrome in South Asia: a systematic review. Int J Diabetes Dev Ctries. 2016; http://doi.org/10.1007/ s13410-015-0365-5.

27. Hong AR, Lim S. Clinical characteristics of metabolic syndrome in Korea, and its comparison with other Asian countries. J Diabetes Investig. 2015;6:508-15.

28. O'Neill S, O'Driscoll L. Metabolic syndrome: a closer look at the growing epidemic and its associated pathologies. Obes Rev. 2015;16:1-12.

29. Al-Nozha MM, Abdullah M, Arafah MR, Khalii MZ, Khan NB, Almazrou YY, et al. Hypertension in Saudi Arabia. Saudi Med J. 2007;28:77-84.

30. Al-Nozha MM, Arafah MR, Al-Maatouq MA, Khalil MZ, Khan NB, Al-Marzouk K, et al. Hyperlipidemia in Saudi Arabia. Saudi Med J. 2008;29:282-7.

31. Bassiony MM. Smoking in Saudi Arabia. Saudi Med J. 2009:30:876-81.

32. Sun K, Liu J, Ning G. Active smoking and risk of metabolic syndrome: a meta-analysis of prospective studies. PLoS One. 2012;7:e47791.

33. Rosano GMC, Vitale C, Marazzi G, Volterrani M. Menopause and cardiovascular disease: the evidence. Climacteric. 2007;10(1):19-24.

34. Park YW, Zhu S, Palaniappan L, Heshka S, Carnethon MR, Heymsfield SB. The metabolic syndrome: prevalence and associated risk factor findings in the US population from the third National Health and nutrition examination survey, 1988-1994. Arch Intern Med. 2003;163:427-36.

35. Boden G, Chen X, DeSantis RA, Kendrick Z. Effects of age and body fat on insulin resistance in healthy men. Diabetes Care. 1993;16:728-33.

36. Al Zenki S, Al Omirah H, Al Hooti S, Al Hamad N, Jackson RT, Rao A, et al. High prevalence of metabolic syndrome among Kuwaiti adults-a wake-up call for public health intervention. Int J Environ Res Public Health. 2012;9: 1984-96.

37. Després JP, Tremblay A, Pérusse L, Leblanc C, Bouchard C. Abdominal adipose tissue and serum HDL-cholesterol: association independent from obesity and serum triglyceride concentration. Int J Obes. 1988;12:1-13.

38. Al-Lawati JA, Jousilahti P. Body mass index, waist circumference and waistto-hip ratio cut-off points for categorisation of obesity among Omani Arabs. Public Health Nutr. 2008;11:102-8.

39. Kim MH, Kim MK, Choi BY, Shin YJ. Educational disparities in the metabolic syndrome in a rapidly changing society-the case of South Korea. Int J Epidemiol. 2005;34:1266-73.

40. Vorster $\mathrm{HH}$. The emergence of cardiovascular disease during urbanisation of Africans. Public Health Nutr. 2002;5:239-43.

41. Zhu YG, loannidis JPA, Li H, Jones KC, Martin FL. Understanding and harnessing the health effects of rapid urbanization in China. Environ Sci Technol. 2011;45:5099-104

42. United Nations - Population Division - Department of Economic and Social Affairs. World Urbanization Prospects 2014. https://esa.un.org/unpd/wup/. Accessed 13 Feb 2017.

\section{Submit your next manuscript to BioMed Central and we will help you at every step:}

- We accept pre-submission inquiries

- Our selector tool helps you to find the most relevant journal

- We provide round the clock customer support

- Convenient online submission

- Thorough peer review

- Inclusion in PubMed and all major indexing services

- Maximum visibility for your research

Submit your manuscript at www.biomedcentral.com/submit
C Biomed Central 